\title{
Is permanent congenital facial palsy caused by birth trauma?
}

\author{
J Hamish E Laing, Douglas H Harrison, Barry M Jones, Gabrielle J Laing
}

RAFT Institute of Plastic Surgery, Mount Vernon Hospital, Northwood, Middlesex J H E Laing

D H Harrison

Department of Plastic and Craniofacial Surgery, Hospital for Sick Children, Great Ormond Street, London B M.Jones

Department of Community Child Health, St Leonard's Hospital, Nuttall Street, London G J Laing

Correspondence to: Hamish Laing, 13 Princess Road, Primrose Hill, London NW1 8JR. Reprints from: The Secretary, RAFT Institute of Plastic Surgery, Mount Vernon Hospital, Northwood, Middlesex HA6 2RN, UK.

Accepted 13 September 1995
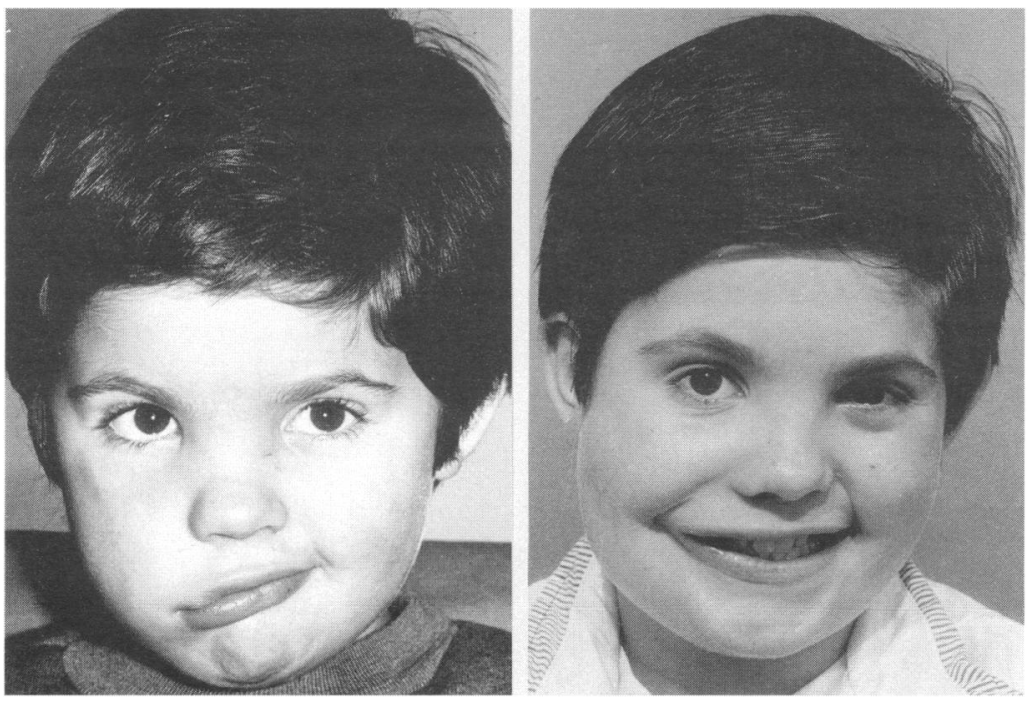

Figure 1 (A) Eight year old boy with right sided 'congenital' facial palsy attempting to smile; $(B)$ one year after facial reanimation surgery using microsurgical nerve and muscle transfers.

Keywords: facial palsy, birth trauma, forceps.

Permanent congenital facial palsy is associated with considerable disfigurement (fig 1). It is distressing for parents and causes functional and emotional problems for the affected child,

\begin{abstract}
Objective-To study the relation between traumatic birth and the development of permanent facial palsy in the newborn.

Design-Retrospective case control study of children with 'congenital' facial palsy. Setting-Two tertiary referral centres for patients with facial palsy.

Subjects-61 children with established facial palsy.

Main outcome measures-Odds ratios of recognised factors for birth injury: maternal primiparity, high birth weight, and the use of obstetric forceps at delivery.

Results-13.2\% of those studied had forceps assisted delivery compared to $10.2 \%$ in the normal population (odds ratio $1 \cdot 34 ; 95 \%$ confidence intervals 0.61 to $\mathbf{2 . 9 7 )} 39.6 \%$ were born to primiparae compared to a national rate of $36.7 \%(1.13$; 0.65 to 1.96 ) and only $18.9 \%$ weighed more than $3500 \mathrm{~g}$ at birth $(0 \cdot 37 ; 0 \cdot 19$ to $0 \cdot 74)$.

Conclusions-There is no association between the development of permanent 'congenital' facial palsy and recognised risk factors for birth injury. These data suggest an intrauterine rather than a traumatic aetiology.

(Arch Dis Child 1996; 74: 56-58)
\end{abstract}

(1)

Mount Vernon Hospital and Great Ormond Street Hospital for Children are tertiary referral centres for facial palsy. ${ }^{4}$ At Mount Vernon Hospital cases were identified from a maintained database of all patients with facial palsy. At the Hospital for Sick Children a generalised diagnostic database was searched and supplemented by reference to the photographic department diagnostic index. Case notes were extracted for patients with congenital facial palsy treated in these units between 1983 and 1993.

Children were included in the study if they had a permanent isolated unilateral facial palsy which was diagnosed at or shortly after birth. They were excluded if any other associated congenital abnormality had been diagnosed before or after referral to the units. Children were considered to have a permanent palsy if it had not recovered by the age of 5 years.

Detailed obstetric histories were obtained from the patient's mother by postal questionnaire, with clarification by telephone where necessary. Further information regarding delivery was obtained from the relevant 


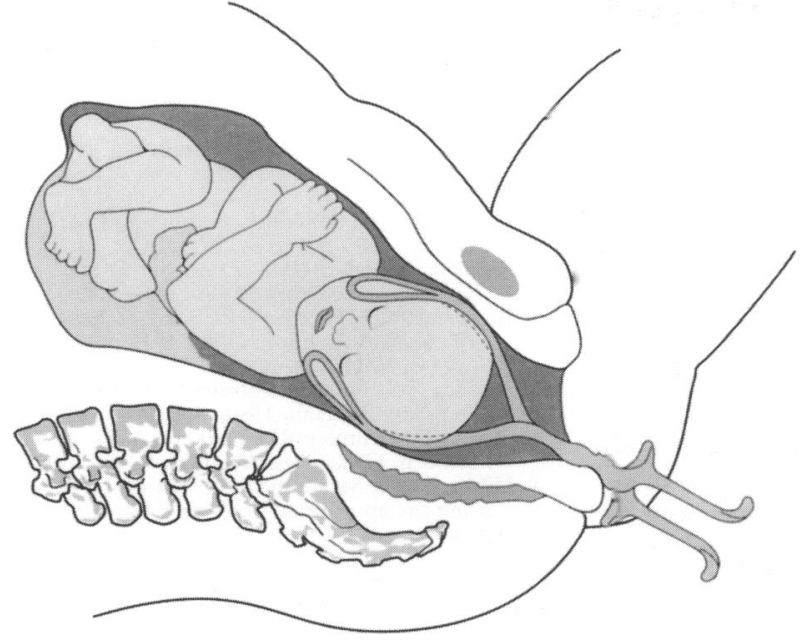

Figure 2 Obstetric forceps being applied to the fetal head. Their proximity to the facial nerve is why forceps are often implicated in congenital facial palsy.

obstetric unit and from the referring clinician's letter.

Data were collected about problems occurring during pregnancy, maternal age and parity, length of gestation, mode of delivery and use of forceps, the indication for instrumental or caesarean delivery, birth weight, and abnormal presentation. The presence of overt soft tissue injuries in the babies was also noted.

The proportions of cases born by forceps delivery, with abnormal presentation, whose birth weight was above $3500 \mathrm{~g}$, or who were born to primiparous mothers, were calculated. These were compared with the population rates for these factors which were obtained from published national data. ${ }^{56}$ The odds ratios and $95 \%$ confidence intervals were obtained by unpaired case control study. ${ }^{7}$

\section{Results}

Sixty one children with congenital facial palsy were identified. Of these eight were excluded because of other congenital abnormalities or syndromes (table 1), leaving a total of 53 children ( 23 boys and 30 girls) with isolated palsy. Response rate to the postal questionnaire was $100 \%$ and telephone follow up for clarification was required in only three cases.

Table 2 summarises the exposure of the children in the study to risk factors for traumatic birth. Seven of these children had a

Table 1 Abnormalities leading to exclusion from the study $(n=8)$. Some children had more than one abnormality

\begin{tabular}{ll}
\hline Congenital abnormality detected & Number \\
\hline Cleft lip and palate & 2 \\
Limb deformity & 3 \\
Hirschsprung's disease & 1 \\
Microtia & 1 \\
DAOM-cardiac syndrome & 1 \\
Abducens palsy & 1 \\
Moebius syndrome & 3 \\
\hline
\end{tabular}

Table 2 Proportion of children with risk factors for traumatic birth

\begin{tabular}{lccll}
\hline Risk factor & Study group & National data & Odds ratio & $95 \%$ CI \\
\hline Forceps delivery & $7 / 53(13 \cdot 2 \%)$ & $68290 / 601460(10 \cdot 2 \%)$ & 1.34 & $0 \cdot 61$ to 2.97 \\
Primiparity & $21 / 53(39 \cdot 6 \%)$ & $240975 / 656234(36 \cdot 7 \%)$ & $1 \cdot 13$ & $0 \cdot 65$ to 1.96 \\
Birth weight $>3500 \mathrm{~g}$ & $10 / 53(18.9 \%)$ & $257191 / 666612(38.6 \%)$ & 0.37 & 0.19 to 0.74 \\
\hline
\end{tabular}

forceps assisted delivery, one of whom had extensive bruising and bilateral hip dislocation consistent with a difficult delivery. He weighed $2450 \mathrm{~g}$ and had fetal distress. Twenty six additional children were born to primiparous mothers or weighed more than $3500 \mathrm{~g}$. None of the big babies was born to primigravidae. There was no clinical evidence of trauma and risk factors for injury were absent in the remaining 20 out of 53 cases.

There was no increased risk of forceps assisted delivery in cases with facial palsy when compared to the population as a whole (odds ratio 1.34: $95 \%$ confidence interval 0.61 to 2.97).

The prevalence of maternal primiparity was no greater among the mothers of affected children than expected from national data (odds ratio 1.13: $95 \%$ confidence interval 0.65 to 1.96 ).

There were many fewer big babies (birth weight $>3500 \mathrm{~g}$ ) in the study group than in the general population (odds ratio 0.37: $95 \%$ confidence interval $0 \cdot 19$ to $0 \cdot 74$ ).

\section{Discussion}

It is well recognised that many children are born with transient weakness of facial expression after traumatic delivery. ${ }^{8}$ The extracranial course of the facial nerve as it leaves the stylomastoid foramen is very superficial and it might easily be contused, particularly in the event of a difficult birth, with impaction of the head against the pelvic outlet. The application of forceps for either traction or rotation might result in neuropraxia of one or both facial nerves (fig 2), particularly if applied incorrectly. ${ }^{9}$ The full recovery which is made by these children ${ }^{10}$ is consistent with current understanding of the regenerative capacity of neonatal tissues and their tendency to heal with less scar tissue than in later life. ${ }^{11}$ Falco and Eriksson ${ }^{3}$ found that palsies with a clearly documented traumatic aetiology all had some degree of recovery, most having complete resolution within a mean of four months postgestation.

Over 40 years ago it was suggested by Hepner ${ }^{12}$ that it was trauma in the birth canal rather than forceps that was responsible. Illingworth emphasised that there are many deformities for which obstetricians are held culpable inappropriately. ${ }^{13}$ None the less, the assumption that birth trauma is responsible for congenital facial palsy continues to be widely expressed. ${ }^{14}$ Many of the parents of affected children in this study had been told by clinicians or midwives that the palsy had been caused by birth trauma. This may have medicolegal consequences and could obscure the true aetiology of the condition.

By comparing the proportion of subjects with factors known to be associated with traumatic birth with those in the population as a whole, this study suggests that the risk of trauma was no higher in the study group than in the general population. In particular, these children were no more likely to have required forceps to assist delivery, nor was there other 
evidence for an association between birth trauma and permanent facial palsy.

The prevalence of major birth defects generally is high in low birthweight babies and low in big babies. ${ }^{15}$ The paucity of high birthweight babies in our study is striking. This further supports our hypothesis that this condition has an intrauterine and not a traumatic aetiology.

These children might also be expected to have associated developmental abnormalities. We accept that it would have been desirable to include developmental assessment in the study; however, the retrospective design and wide catchment of the two centres precluded this.

While the aetiology remains uncertain we should not allow the blame for permanent facial palsy to continue to fall upon the obstetrician or midwife.

This study was funded by the Restoration of Appearance and Function Trust (RAFT). We would like to thank Dr Martyn Sherriff, PhD, United Medical and Dental School, London, for assistance with statistical analysis and Jane Fallows, Medical Illustrator, Mount Vernon and Watford Hospitals NHS Trust, for fig 2 .

1 Perinatal conditions. In: World Health Organisation, Geneva, ed. International classification of diseases $9 t h$ revision with UK amendments and extensions. London: NHS Management Executive, 1978
2 Levine MG, Holroyde J, Woods JR, Siddiqi TA, MacHenry $S$, Miodovnik M. Birth trauma: incidence and predisposing factors. Obstet Gynecol 1984; 63: 792-5.

3 Falco NA, Eriksson E. Facial nerve palsy in the newborn: incidence and outcome. Plast Reconstr Surg 1990; 85: $1-4$.

4 Harrison DH. Current trends in the treatment of established unilateral facial palsy. Ann R Coll Surg Engl 1990; 72: 94-8.

5 Estimated total deliveries, number and percentage mode of delivery, 1980 (revised). In: OPCS, ed. Hospital inpatient delivery, 1980 (revised). In: OPCS, ed. Hospital inpatient
enquiry series MB4. London: Office of Population enquiry series MB4. London: Office

6 Birth statistics 1980. In: OPCS, ed. Hospital inpatient enquiry series SD52A. London: Office of Population Censuses and series $S D 52 A$. L
Surveys, 1984 .

7 Altman DG. Practical statistics for medical research. London: Chapman and Hall, 1991: 268-9.

8 Smith JD, Crumley RL, Harker LA. Facial paralysis in the newborn. Otolaryngol Head Neck Surg 1981; 89: 1021-7.

9 Hibbard BM, McKenna DM. The obstetric forceps - are we using the appropriate tool? Br $\mathcal{F}$ Obstet Gynaecol 1990; 97: 374-80.

10 Kumari S, Bhargava SK, Choudhury P, Ghosh S. Facial palsy in newborn: clinical profile and long-term follow-up. Ind Paediatr 1980; 17: $917-21$.

11 Lin KY, Posnick CP, Al-Quattan MM, Vasjar J, Becker LE. Fetal nerve healing: An experimental study. Plast Reconstr Furg 1994; 93: 1323-33.

12 Hepner WR. Some observations on facial paresis in the newborn infant: etiology and incidence. Pediatrics 1951; 8: newborn infant: etiology and incidence. Pediatrics 1951; 8: 494-7.

3 Illingworth RS. Why blame the obstetrician? A review. $B M F$ 1979; i: 797-801.

14 Louis SM, McKnight P. Medical causes of facial paralysis, including Bell's palsy. In: Rubin LR, ed. The paralyzed face. St Louis: Mosby-Year Book, 1991: 87-90.

15 Mili F, Edmonds LD, Khoury MJ, McClearn AB. Prevalence of birth defects among low-birthweight infants. A population study. Am $\mathcal{F}$ Dis Child 1991; 145: 1313-8. 